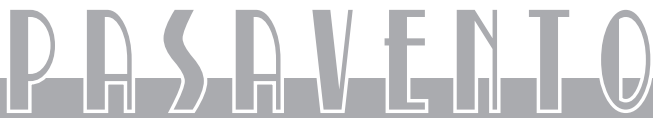

Revista de Estudios Hispánicos

Vol. I, n. ${ }^{\circ} 1$ (invierno 2013), pp. 113-124, ISSN: 2255-4505

\section{EL ESPACIO COMO SUJETO DE LA TRANSGRESIÓN FANTÁSTICA EN EL RELATO "LOS PALAFITOS" (ÁNGEL OLGOSO, 2007)}

\author{
Patricia García García \\ Dublin City University / Trinity College
}

\begin{abstract}
Los espacios se han multiplicado, fragmentado y diversificado. [...] Vivir es pasar de un espacio a otro haciendo lo posible por no golpearse.
\end{abstract}

Georges Perec, Especies de espacios

\section{ESPACIO Y TEXTO}

Empezaremos repitiendo lo que ya numerosos estudios filosóficos han identificado a lo largo de la Historia: la experiencia del espacio está directamente relacionada con la construcción humana de la realidad, como se lee en el Timeo de Platón (360 a. C.), en Kant, en la Fenomenología de la percepción de Maurice Merleau-Ponty (1945), o en "Construir, Habitar, Pensar" de Martin Heidegger (1951), por citar algunos ejemplos.

Junto con el tiempo, y podríamos añadir el lenguaje, la dimensión espacial nos proporciona un esquema de delimitación, referencia y jerarquía sin el cual no podríamos codificar lo que nos rodea. Precisamente la dificultad conceptual del espacio radica en que es tanto dimensión física (en la que nos movemos), como herramienta que utilizamos para aprehender el entorno (esas famosas gafas espacio-tiempo de Kant a través de las cuales podemos codificar la experiencia sensible).

La etimología de la palabra "arquitectura" claramente concentra esta interdependencia entre el espacio y la construcción de lo real. Del griego arché (el principio u origen) y tektoon (obra, creador de artificio), el arquitecto es el que transforma el caos original en espacio definido, habitable y sobre todo abarcable para el humano: "Cuando el arquitecto traza una línea, el espacio, hasta entonces 
similar a la superficie del océano o a un desierto de arena, sin caminos que orienten al ser viviente, de pronto se segrega" (Azara 2005: 60). Es el arquitecto el que construye la realidad del hombre; el que "pone cotas al mundo, humanizándolo" (Azara 2005: 18) ${ }^{1}$.

El espacio es así un vehículo clave para aprehender y construir tanto la realidad física, así como, evidentemente, la realidad textual (Ryan 2012). La importancia del efecto de realidad como requisito en el texto fantástico es un aspecto enfatizado ya desde los estudios fundacionales de Pierre-Georges Castex (1951), Roger Caillois (1958) y Louis Vax (1960). Sin embargo, cómo el espacio contribuye a transgredir el efecto mimético del texto fantástico es un aspecto que hasta la fecha no ha sido analizado en profundidad. Si bien hay algunos estudios que se centran en el lugar donde ocurre el acontecimiento imposible, como el castillo, la casa o la ciudad (Jackson 1981, Aguirre 1990, Fournier Kiss 2007), hay muy pocos en cuanto a las transgresiones a través de la dimensión espacial. Por este motivo, en el presente artículo queremos sustituir la habitual pregunta de "¿dónde ocurre lo sobrenatural?", que aborda el espacio como escenario en el que opera otro sujeto fantástico, por la de "¿qué hecho fantástico genera el espacio y cómo lo hace?"; es decir, vamos a presentar el espacio como sujeto transgresor de la realidad establecida en el texto.

En la primera parte de este estudio ampliaremos esta reflexión inicial sobre el tratamiento del espacio en la crítica de lo fantástico, antes de pasar al análisis textual en la segunda parte. Nos vamos a centrar en el cuento "Los palafitos" (Ángel Olgoso 2007), ya que en él se distinguen varios niveles de la experiencia y transgresión espacial: el ámbito topográfico (el espacio geográfico y entorno natural), el arquitectónico (el espacio construido y articulado) y el cartográfico (el espacio representado y reproducido). Finalmente, abordaremos el espacio entendido como marco contingente de mundos ficcionales. Analizaremos la idea de mundo a lo largo del relato para explorar la inquietante metáfora final que apunta a la sustitución del espacio como referente, figura que expondremos como rasgo distintivo de lo fantástico posmoderno.

\subsection{El esPacio, ¿MOtivo fantástico?}

El espacio ha sido, hasta la fecha, uno de los grandes ignorados tanto en las reflexiones teóricas como temáticas de lo fantástico. En la mayoría de estudios, el espacio es abordado como escenario físico donde se desarrolla la acción. Así, si se menciona, queda reducido a estrategia mimética para intensificar ese efecto de realidad del que habla Roland Barthes (1968: 84-89), tan fundamental en lo fantástico. Roger Caillois por ejemplo menciona: "El marco de lo fantástico no es el bosque encantado de La Bella Durmiente, sino el opaco universo administrativo de la sociedad contemporánea" (1970: 16)². David Roas comenta la

\footnotetext{
${ }^{1}$ Acerca del arquitecto como sujeto divino en los mitos fundacionales, ver: Castillos en el aire: mito y arquitectura en Occidente (Azara 2005: 20).

2 Las cursivas son mías.
} 
necesidad de "ambientar la historia en lugares reales" (2001: 26) y Rosalba Campra enfatiza que "la descripción minuciosa de espacios" es una de las técnicas principales para incrementar la verosimilitud en el texto fantástico (2001: 176) .

Otros trabajos efectúan un análisis diacrónico de la ambientación que envuelve el fenómeno fantástico. Un ejemplo es el famoso estudio de Rosemary Jackson, Fantasy: the Literature of Subversion (1981), donde analiza los cambios topográficos en distintas etapas de esta forma narrativa. El "espacio gótico confinado como espacio de máxima transformación y terror" (1981: 47) ${ }^{3}$ constituye, según la autora, el hilo conductor entre los diferentes lugares predominantes en lo fantástico, desde el castillo remoto y aislado a la ciudad kafkiana de la modernidad. Una perspectiva similar aporta Corinne Fournier Kiss en su excelente estudio sobre la ciudad europea moderna. En él analiza la fascinación y ansiedad que provoca la urbe a principios del siglo xx: "lo fantástico moderno es un fantástico urbano: a partir de finales del siglo xIx es en casa, en la calle y en el apartamento donde lo fantástico aparece" (Fournier Kiss 2007: 25) ${ }^{4}$.

Estas aproximaciones demuestran un aspecto fundamental de la relación entre el espacio y lo fantástico: entendido aquí como ambientación, el espacio no es en absoluto neutro, premisa central del llamado "giro espacial" ${ }^{5}$. También en la narrativa fantástica, los estudios mencionados reflejan que el espacio es un elemento clave para trazar las distintas evoluciones socio-culturales que afectan a la literatura. Sin embargo, estas perspectivas teóricas abordan el espacio como categoría estable: lo imposible no está asociado a las leyes del espacio físico sino que su función se limita a "contener" lo sobrenatural, ya sea la criatura (como la clásica casa encantada por fantasmas) o el evento fantástico (por ejemplo la habitación donde ocurre la metamorfosis de Gregorio Samsa).

En cuanto al espacio como categoría temática en lo fantástico, se observa una similar falta de atención. En la extensa variedad de listas temáticas, si aparece, a menudo se presenta como anexo al tiempo. Louis Vax, por ejemplo, simplemente lo menciona entre "las alteraciones de la causalidad, el espacio y el tiempo" (1973: 30), y Tzvetan Todorov incluye en las categorías del Yo "las transformaciones del tiempo y espacio" (1970: 120). Rosalba Campra es una de las pocas en reconocerlo como categoría autónoma. Dentro de lo que ella denomina "elementos de la enunciación", las distorsiones del "acá/allá" dan lugar, según ella, a la anulación de la distancia (2001: 165). Campra, sin embargo, olvida que el espacio no es solo distancia. Como indica el antropólogo Otto Friedrich Bollnow (1969) en su estudio sobre la espacialidad en nuestra construcción de

\footnotetext{
3 De no incluirse directamente dentro del texto, todas las traducciones son mías: "the Gothic enclosure as space of maximum transformation and terror" (Jackson 1981: 47).

4 "Le fantastique moderne est un fantastique urbain: c'est désormais chez soi, dans sa rue ou dans son appartement, que le fantastique se manifeste" (2007: 25).

5 Para una perspectiva crítica sobre las aportaciones teóricas del "giro espacial" en los estudios literarios (incluyendo conceptos centrales como el cronotopo bajtiniano, las aproximaciones fenomenológicas y socio-urbanas, y teorías de mundos posibles en ficción), ver: N. Álvarez Méndez (2002), B. Westphal (2007), W. Hallet y B. Neumann (eds.) (2009), y M. P. Celma y J. R. González (2010).
} 
lo real, el espacio provee también un sistema de ejes de referencia y límites que definen el entorno, así como un orden jerárquico de cuerpos. De este modo, a la categoría que propone Campra del "acá/allá", habría que añadirle otros aspectos fundamentales como el "en" (jerarquía entre cuerpo contingente y elemento contenido) y el "ancho/alto/largo" (volumen y tridimensionalidad).

A pesar de la escasa atención que la crítica de lo fantástico ha dedicado a la categoría del espacio, su función es clave en la configuración del efecto mimético (siempre base sobre la que opera lo fantástico), como ya hemos indicado al principio de este artículo. Sin embargo, no es hasta finales de la segunda mitad del siglo xx cuando se observa que el espacio se convierte en verdadero objeto de fascinación entre los escritores de lo fantástico, como expondremos a continuación.

\subsection{Espacio y La construcción de lo Real en la Posmodernidad}

¿Qué función tiene el espacio en la organización de nuestra experiencia hoy en día? La compleja visión posmoderna de la relación espacio/realidad no puede ser entendida sin tener en cuenta las revoluciones en la física a principios del siglo $\mathrm{xx}$, impulsadas por las teorías de la relatividad de Einstein y el desarrollo de las teorías cuánticas. La idea de mundo como máquina perfecta que la mecánica de Newton había consolidado durante tres siglos se ve forzada a reconocer sus limitaciones y paradojas. El viejo paradigma de espacio absoluto como marco de referencia físico estable, no alterado por lo que contiene, a través del cual se mide toda distancia y velocidad, y sometido a las certezas de la geometría euclidiana, cede a las incertidumbres del relativismo y la física cuántica.

Es este el inevitable fin del modelo de conocimiento científico positivista dominante a finales del siglo xIX y el principio de un contexto relativista. Bajo este nuevo paradigma, la idea tranquilizadora de la dimensión espacial estable, absoluta e inequívoca queda desbancada por un modelo del espacio complejo, fluctuante, impredecible y vulnerable a la mirada del individuo. La perspectiva absoluta queda debilitada para dar pie a una mirada multifocal y construida por el espectador que la observa. Surge así una idea de realidad incierta, desprovista de un centro de referencia estable, como ya expresaba Nietzsche con su célebre metáfora de la muerte de Dios. Se trata de una visión del mundo que no solo no excluye sino que tampoco prioriza. Ese orden espacial tan importante para estructurar lo real se disuelve dando lugar a, como lo expresa Bertrand Westphal, "una jerarquía desacralizada donde toda idea de prioridad se desvanece" (2007: $14)^{6}$.Por lo tanto, en relación a la pregunta planteada al inicio de esta sección, podemos responder que el espacio, entidad clave para configurar nuestra experiencia de realidad, se ha convertido en la Posmodernidad en un cómplice menos fiable. Es este, a nuestro parecer, un aspecto central que explica el auge de textos en la literatura fantástica contemporánea donde la dimensión espacial se convierte en fuente de inquietud temática. Los espacios atrapan al individuo

\footnotetext{
6 "une hiérarchie désacralisée d'où toute idée de priorité s'est évanouie" (2007: 14).
} 
("Lost in the Funhouse", de John Barth), lo expulsan como en "Casa Tomada" de Julio Cortázar, se yuxtaponen y fragmentan como la identidad de sus habitantes ("Relámpagos", de Ángel Olgoso), son elásticos como la casa de "The Enormous Space" (J. G. Ballard), son intermitentes como "La casa feliz" de José María Merino, etc. En resumen, perforan el modelo de realidad estable positivista, como esos agujeros negros de "Mi hermana Elba" (Cristina Fernández Cubas, 1980). Cito al mismo Ángel Olgoso, quien hace referencia a este aspecto en una entrevista:

[...] unos de mis motivos para escribir es el placer que me procura intentar despojar al lector de esas gafas [espacio-tiempo], impidiéndole una aceptación sumisa de las leyes espacio-temporales. (Olgoso en Muñoz 2009)

Así, frente a la escasa utilización del espacio como elemento imposible en el texto fantástico del siglo XIX, en lo que denominamos fantástico posmoderno se observa una proliferación de textos en los que el espacio pasa a ser sujeto fantástico, y, por lo tanto, más que nunca realza la necesidad de un marco teórico que aborde este fenómeno y que, como he mencionado, no se ha desarrollado en profundidad hasta la fecha ${ }^{7}$.

Si bien sistematizar la transgresión de las leyes físicas del espacio en el relato fantástico sobrepasa la dimensión de este artículo, proponemos centrarnos en un texto ejemplar para analizar cómo el espacio trasciende esa función estática que se le ha asignado tradicionalmente y pasa a ser un elemento activo en la construcción de la transgresión fantástica ${ }^{8}$.

\section{2. "Los palafitos" (Ángel Olgoso, los demonios del lugar, 2007)}

Ángel Olgoso (Granada, 1961) es un escritor que sin duda se mueve con asiduidad en los confines del relato corto fantástico, como consta en Cuentos de otro mundo (2003), Los demonios del lugar (2007), Astrolabio (2007) y La máquina de languidecer (2009). "Los palafitos" (2007), relato que hemos seleccionado para este artículo, ha sido recogido recientemente como exponente central de la obra del autor en Perturbaciones: Antología del relato fantástico español actual (2009).

El argumento es el siguiente: el protagonista, experto en botánica, nos cuenta que se pierde durante una de sus habituales excursiones por el campo, aunque sabe que está a un radio de diéz kilómetros de una ciudad que conoce. Por el camino encuentra a un pescador que lo invita a descansar en su aldea, situada junto a un lago, dato que ya sorprende al narrador, quien sabe no es una zona lacustre. La llegada a la aldea todavía le aguarda más sorpresas: sus habitantes viven en palafitos, esas viviendas primitivas construidas sobre

\footnotetext{
7 Me rijo por la conceptualización de lo fantástico posmoderno de David Roas en el reciente trabajo Tras los límites de lo real: Una definición de lo fantástico (2011b: 143-156).

8 El tiempo es también un factor importante en "Los palafitos". De las distorsiones del eje temporal se ha ocupado David Roas en su artículo "Cronologías alteradas: la perversión fantástica del tiempo" (2011a).
} 
pilotes en el agua. A medida que va conversando con el pescador, la extrañeza se va acentuando. Todo indica que esta comunidad se ha detenido en el pasado: sus costumbres arcaicas (el trueque y los entierros bajo el dolmen), materiales y utensilios (pieles, cuencos, arcilla y madera), alimentos (tapioca, leche de cebú y pescado seco) y supersticiones (la noche es un ente amenazador y sobrenatural). En la aldea desconocen el hormigón, asfalto, ladrillo y cristal.

Una vez caída la noche, el pescador saca un pergamino con el mundo dibujado y es en ese momento cuando lo improbable se transforma en imposible. El mapa muestra un mundo que se corresponde con la geografía del narrador pero únicamente poblado de palafitos. Estas construcciones invaden todo, incluso las regiones en las que nunca hubo palafitos en el pasado (este último detalle es crucial, como explicaremos más adelante). Ante semejante revelación, el protagonista pierde toda certeza acerca del mundo que creía conocer. La historia universal se desploma ante sus ojos. El relato se cierra con un desenlace imprevisto para mayor desconcierto del lector: el viajero perdido acepta con naturalidad el mundo de palafitos y se somete a esta nueva realidad.

\subsection{TOPOgRAfía: EL PASEO}

Las características geográficas del espacio, como el paisaje, son muy importantes sobre todo al principio del relato. En el primer párrafo el personaje está paseando sin rumbo fijo por la naturaleza, entregado "a un paseo despreocupado pero vigoroso, llevado por la deliciosa brisa que lame las laderas de las colinas" (Olgoso 2007: 45). Esta inmersión en la topografía de la zona se genera no solo a través de la vista sino también el oído ("el canto exultante del aligrís" [45]), tacto (la textura de la "hoja atrapadora de insectos" [45]) y olfato (el "aroma del majuelo" [45]). Así, vagabundeando absortos como el personaje, nos hemos ya extraviado en el dominio fantástico. Este cruce de umbral se ha producido a través de un sutil detalle que se esconde en las citas que acabamos de mencionar. El lector con conocimientos de fauna y flora se habrá dado cuenta de una incoherencia en este primer párrafo, relacionada con dos especies que observa el narrador en su paseo: el aligrís y el majuelo. El aligrís (o trompetero ala gris) es un ave grisácea que únicamente se encuentra en el Amazonas. El majuelo, sin embargo, es una especie de seto de las rosáceas que se encuentra en Europa, y algunas partes de África y Asia, pero no en la zona amazónica. Puesto que estas dos especies no pueden coexistir en el mismo terreno geográfico, estamos ya situados de inmediato en un espacio imposible. Seguimos con las anomalías relacionadas con la geografía: el protagonista acompaña al pescador a su aldea para refugiarse de la noche. Esta se halla sobre un lago, pese a que en el espacio referencial del protagonista esto es improbable ("en una región seca como la nuestra, carente por completo de corrientes subterráneas y zonas dulceacuícolas" [46]). 


\subsection{Arquitectura: la aldeA}

El descubrimiento de los palafitos produce todavía más estupor en el narrador, pues como dice, "no hay palafitos en la ciudad, ni siquiera en el país, de hecho dudo que aún existan palafitos en algún lugar que no sea una reproducción turística de la Edad del Bronce, o quizás en un poblado asiático o una isla perdida" (49). En el marco referencial del pescador, los elementos relacionados con la modernidad como la ciudad, el asfalto y los edificios no existen. "Palabras así no las hay, señor", dice, a lo que el viajero replica: "Yo mismo vivo en un edificio de hormigón, ladrillo y cristal de doce plantas"; de nuevo el pescador contesta: "Señor, no habla por su boca la razón natural. ¿Doce cuerpos, dice?" (53). Nos damos cuenta de que estamos en un marco temporal diferente, que entra en conflicto con el del protagonista: al descubrir los palafitos, pensamos habernos transportado al pasado.

El ingreso en este terreno es vivido como el retorno a la pureza original. De nuevo, esto queda plasmado a través de la "mirada sensorial" (48). "Todo cobraba relieve" (48); el olfato, "un tufo almizclado a cueros, salazones y cocos recién partidos"; la vista, "la luz más cálida", "Ios colores más intensos", y el oído, "la arremolinada eclosión aquí y allá de tallos de carrizo" (48).

En el momento de la caída de la noche, la oposición espacio habitable/ caos se refleja con el contraste entre la lumbre interior y oscuridad circundante ("Ese rociado de luz de un amarillo arcaico, como de fuego de fanal atizado en caverna milenaria, esparció sus regueros en todas direcciones" [56]). Por eso, cuando el protagonista pretende abandonar el espacio delimitado por la aldea de los palafitos, el pescador responde: "Me sorprende que lo olvide. Todos los que desafían la oscuridad pierden pie en la vida" (55). El exterior de la aldea es "un peligro que de alguna manera, sujeto a leyes desconocidas y arbitrarias, amenaza desde el fondo de la tierra y de las aguas" (59). De esta forma, en el texto se genera la interesante imagen de la aldea como espacio ganado al caos. La luz es un elemento clave que distingue lo dominado frente a lo indómito que queda fuera de sus confines. El centro constituye un hogar, es el espacio iluminado presidido por el fuego. Los palafitos poseen así además una dimensión simbólica relacionada con la función primigenia de la arquitectura, lo cual refuerza esa imagen de la aldea de los palafitos como territorio originario, el único espacio (el arché) de la existencia humana:

El gesto primordial del arquitecto delinea una nítida frontera entre nuestro mundo y el de los otros (las alimañas, los muertos, los emisarios de la noche, los bárbaros, los seres [...]). El espacio iluminado se confronta con el mundo de las tinieblas. Se instituye un lugar habitable porque, más allá de la barrera que, como un surco profundo, abre la línea en la tierra, aparece el espacio en el que la vida no puede desarrollarse, los dominios de la noche y de los muertos. (Azara 2005: 60) 


\subsection{Cartografía: el mapa}

El efecto fantástico irrumpe definitivamente cuando el pescador despliega el mapa que muestra el mundo invadido de palafitos. En ese objeto los palafitos "se prodigaban por todo el planeta: vi palafitos asentados en valles fértiles, entre los penachos de nieve de las montañas, entre los bosques a la luz de la luna, como nidales al borde de acantilados" (58). El mapa muestra un espacio geográfico exactamente como el del narrador, pero con la imposible omnipresencia de palafitos, incluso en lugares donde en la antigüedad nunca los hubo. Y a raíz de esto se produce el derrumbe epistemológico y ontológico.

El descubrimiento del mapa imposible genera en el narrador ese "miedo totalizador que se experimenta cuando desaparece bruscamente, bajo nuestros pies, la tierra de las certezas" (57). A continuación, el narrador dedica más de tres páginas a desarrollar una de las metáforas espaciales más bellas del texto: la historia de la humanidad se derrumba en la mente del narrador a través de sus construcciones arquitectónicas. Se desploman las pirámides, castillos, palacios, iglesias, catedrales, anfiteatros, templos, mausoleos y demás símbolos del progreso humano:

La verosimilitud que antes me llegaba en leves y dispersas oleadas, me alcanzó ahora de lleno, de forma instantánea: vastos tapices de civilización se desintegraban ante mis ojos como por ensalmo; las infinitas y vivas ciudades, los encajes de colosales arquitecturas, se hundían de nuevo en repentinos mares de polvo y de hierba; la catedral de los logros humanos, trabajosamente erigida, se desleía en gravilla y aire, una multitudinaria y frenética hueste de titanes, un laborioso ejército de canteros, una batalladora tropa de constructores de imperios, una tumultuosa sucesión de generaciones se disipaban como espectros colectivos en el vacío, en la esterilidad, en la nada. (Olgoso 2007: 59)

Las voces arquitectónicas que han levantado las crónicas de la humanidad ("piedra, mármol, campanas y martillos" [59]) quedan silenciadas con el inesperado mapa, que borra toda referencia física, geográfica, social y cultural. Como indica el mismo autor, el efecto perseguido era "la progresiva demolición de la historia universal" (Olgoso en Muñoz 2009), y así lo hace el despliegue del mapa, momento que sintetiza una quiebra absoluta del marco referencial del personaje.

De nuevo, la luz se vuelve un elemento clave que identifica espacio con la realidad conocida: la lumbre, fundadora del espacio humano, se va extinguiendo como las certezas del personaje acerca de qué es lo conocido y verdadero: "La fantasmagoría desplegada impávidamente tras el fortuito encuentro con el pescador disolvía los recuerdos, apagaba luces y faros, atomizaba volúmenes de toda clase y tamaño [...]" (60).

El viajero experimenta este desplome de lo conocido como un descenso al vacío, y posterior retorno "al fresco comienzo, a su semilla, a su matriz intacta" $(59)^{9}$.

${ }^{9}$ Esta imagen recuerda a las metáforas arquitectónicas que Descartes reitera para expresar la 120 Pasavento. Revista de Estudios Hispánicos, vol. I, n. ${ }^{1}$ (invierno 2013), pp. 113-124, ISSN: 2255-4505 


\subsection{ESPACIO COMO MUNDO FICCIONAL}

Una vez establecido cómo se genera la transgresión fantástica mediante la topografía, arquitectura y cartografía, nos queda analizar el espacio en su dimensión más abstracta: como mundo ficcional o "receptáculo" contingente de toda materia existente.

A nuestro parecer, la complejidad central del relato se halla en la disposición de los espacios o mundos narrativos. ¿Qué mundo contiene al otro y cómo se hallan dispuestos? Para abordar esta cuestión, proponemos un ejercicio cartográfico de estos dominios, que permitirá "visualizar" las diferentes ideas de mundo que se proponen en el relato.

Ya hemos indicado que hay dos mundos narrativos en el texto. Por una parte está el mundo referencial del viajero, que comparte tiempo y espacio con el lector, con ciudades, asfalto y "edificios sólidos a ras de suelo" (Olgoso 2007: 53). Desde este marco referencial, el otro mundo, el que representa el mapa de los palafitos, es arcaico. Sin embargo, como vamos a ver, la idea de mundo pasado implica un presente de referencia, por lo que nuestro marco o modelo de mundo se mantendría en su posición central. Pero es precisamente esta función referencial la que queda aniquilada al final del relato.

Podemos distinguir tres configuraciones jerárquicas entre los dominios o, dicho de otra forma, tres "mapas ontológicos" distintos a lo largo del relato.

Al principio, el narrador (y por extensión el lector) cree haber accedido a una región que desconoce. La aldea de los palafitos es una zona extraordinaria en su entorno. Así, dice el narrador: "ustedes son la excepción... Una excepción del todo pintoresca e imposible en estas latitudes" (59). Por lo tanto, el marco de referencia del personaje queda quizás extrañado por este hecho pero no invalidado. La aldea no es más que una porción contenida en el mundo del viajero; una "interpolación" o agujero de lo fantástico en nuestra realidad.

Sin embargo, a medida que avanza la narración, hay demasiados elementos que contradicen este primer "mapa ontológico". Conversando con el pescador, el narrador descubre que en la aldea se desconocen los elementos de la modernidad. Cree haber retrocedido en el tiempo. Entonces pensamos que ha abandonado su época, pero aún así su mundo sigue actuando como referencia. Nos hallaríamos, de este modo, ante una distorsión fundamentalmente del eje temporal: un salto al pasado. En nuestra cartografía mental, esta figura muestra una "yuxtaposición" de dos épocas (presente-pasado) contenidas en la misma idea de mundo.

Finalmente, el momento culminante llega con el mapa que muestra un mundo con palafitos incluso donde nunca los hubo en la antigüedad. No hemos simplemente dado un salto al pasado mientras que el marco de referencia presente nos sigue aguardando en alguna parte, sino que el mundo de los palafitos

puesta a prueba de toda certeza en su Discurso del método (1637). Recordemos que, para este filósofo, la razón aparece como algo que el hombre necesita construirse para cobijarse de la incertidumbre y del caos. La falta de conocimiento equivale a la intemperie, la desprotección, el desamparo (Descartes 1983: 63-64). 
es prueba irrefutable de que las dos ideas de mundo (la del protagonista y la de los palafitos) no pueden coexistir. El personaje entonces acepta, con una naturalidad que deja estupefacto al lector, esta nueva realidad fantástica. Cierra el relato explicando que desearía hallarse esa noche con su esposa "vestida de yute y adornada con brazaletes y conchas, guarecidos ahí de la intemperie y la oscuridad, mutuamente reconfortados, acodados ambos en nuestro palafito" (62).

En resumen: primero, a través de los detalles geográficos el protagonista percibe que ya no está en el espacio referencial cotidiano sino en una región excepcional; segundo, la inmersión en la aldea de los palafitos demuestra que ya no se halla en el mismo marco temporal; y tercero, a través del mapa, se da cuenta de que no solo ya no está en el mismo tiempo sino que debe abandonar la idea de mundo que creía conocer. Se trata, al cierre del relato, de una distorsión del espacio entendido como dimensión que alberga el mundo, en la que el dominio referencial no solo queda extrañado sino destruido por otra imagen de mundo. Finalmente, ¿qué representa esta última figura?, ¿qué significado alberga este desplome del mundo que pensábamos real y único?

\section{Conclusión: EL DESPLOME DE LA REALIDAD}

El asalto sobrenatural del espacio entendido como mundo es, en nuestra opinión, un motivo característico de lo fantástico posmoderno. El texto describe cómo nuestro modelo de mundo deja de ser el único modelo referencial. Es esta una manera de ilustrar la destrucción de lo absoluto y unívoco. Frente a la solidez del mundo real que presupone lo fantástico tradicional, como indicaba la célebre fórmula de Roger Caillois ${ }^{10}$, nos hallamos ahora ante un fantástico que, al contrario, es consciente de anclarse en un modelo de realidad (extratextual) frágil. Surge así una modalidad de lo fantástico que no busca únicamente atacar la idea de realidad a través de la excepción (como puede ser la aparición del fantasma), sino que pretende revelar la artificialidad de este modelo, en este caso ofreciendo otros modelos de mundos verosímiles, como el mundo de los palafitos.

Siguiendo a Davies, si "la totalidad del espacio es el universo y la totalidad del tiempo es la historia del universo" (1996: 254), hemos visto cómo en el relato las categorías tiempo y espacio colaboran para cuestionar la validez de nuestro modelo de universo. Estamos así de acuerdo con la reflexión de Juan Jacinto Muñoz Rengel, quien indica que la naturaleza del mundo y las teorías del universo son líneas temáticas predominantes en lo fantástico contemporáneo, precisamente para expresar la precariedad del modelo de realidad sobre el que se ancla (2010: 8).

Como hemos observado en el cuento de Olgoso, este aspecto se traduce en el cuestionamiento del espacio narrativo a varios niveles, culminando en este concebido como totalidad, como orden en el que se mueven los personajes a

10 "lo fantástico supone la solidez del mundo real, pero para poder mejor devastarlo" (Caillois 1970: 21).

122 | Pasavento. Revista de Estudios Hispánicos, vol. I, n. ${ }^{1}$ (invierno 2013), pp. 113-124, ISSN: 2255-4505 
través de un sistema de regularidades; es decir como marco de referencia estable. Este tratamiento temático del espacio narrativo demuestra una importante diferencia con lo fantástico tradicional. Frente a la presupuesta pasividad del decorado (por eso raramente es el motivo sobrenatural en los relatos del siglo XIX), aparece aquí la idea del espacio como entidad que fracasa en su función contingente y estructuradora de la realidad textual. No se trata de un simple trasfondo realista, estable e inocente, ni de una dimensión subyugada a otro motivo fantástico, sino que se convierte en el sujeto de la transgresión fantástica. Así, no conforme con deslizarse por esos escenarios tradicionalmente neutros, lo fantástico toma también los espacios.

Ante un modelo de realidad extratextual descentrado y sin fundamentos estables que tomar como referencia, las transgresiones fantásticas de la dimensión espacial expresan la inseguridad del individuo en un mundo donde apenas puede orientarse y de cuya ontología desconfía. Si, como decía Maupassant "solo se tiene miedo realmente de lo que no se comprende" (1996: 152), y ese miedo incomprensible es el que forma el eje de lo fantástico, no sorprende que la dimensión espacial haya entrado definitivamente en la esfera temática de la literatura fantástica actual. Este hecho revela la necesidad de que ese "giro espacial" en las aproximaciones teóricas literarias de las últimas décadas se extienda también a esta forma narrativa.

\section{OBRAS CITADAS}

Aguirre, Manuel (1990): The Closed Space: Horror Literature and Western Symbolism. Mánchester, Manchester University Press.

Álvarez Méndez, Natalia (2002): Espacios narrativos. León, Universidad de León.

Azara, Pedro (2005): Castillos en el aire: Mito y arquitectura en Occidente. Barcelona, Editorial Gustavo Gili.

Barthes, Roland (1968): "L'Effet de réel". En: Communications, n. ${ }^{\circ} 11$, pp. 84-89.

Bollnow, Otto Friedrich (1969): Hombre y espacio. Barcelona, Labor.

Caillois, Roger (1970): Imágenes. Imágenes. Barcelona, Edhasa.

Campra, Rosalba (2001): "Lo fantástico: una isotopía de la transgresión". En: Roas, David (ed.): Teorías de lo fantástico. Madrid, Arco/Libros, pp. 153-191.

Castex, Pierre-Georges (1951): Le Conte fantastique en France de Nodier à Maupassant. París, José Corti.

Celma, María Pilar y González, José Ramón (2010). Lugares de ficción: la construcción del espacio en la narrativa actual. Valladolid, Universidad de Valladolid.

Davies, Paul Charles William (1996): El espacio y el tiempo en el universo contemporáneo. México D. F., Fondo de Cultura Económica.

Descartes, René (1983): Discurso del método. Barcelona, Ediciones Orbis.

Fournier Kiss, Corinne (2007): La Ville européenne dans la littérature fantastique du tournant du siècle (1860-1915). Lausana, L'âge d'homme.

Hallet, Wolfgang y Neumann, Birgit (eds.) (2009): Raum und Bewegung in der Literatur: Die Literaturwissenschaften und der Spatial Turn. Bielefeld, Transcript. 
Heidegger, Martin (2001): "Construir, Habitar, Pensar". En: Conferencias y artículos. Barcelona, Ediciones Del Serbal.

Jackson, Rosemary (1981): Fantasy: the Literature of Subversion. Nueva York, New Accents.

Maupassant, Guy de (1996): "El miedo". En: El Horla y otros cuentos de crueldad y delirio. Madrid, Valdemar.

Merleau-Ponty, Maurice (1997): Fenomenología de la percepción. Barcelona, Península.

Muñoz, Miguel Ángel (2009): "Entrevista a Ángel Olgoso". Blog El síndrome Chéjov: http://elsindromechejov.blogspot.com/2009/11/angel-olgoso-siempre-me-haobsesionado.html. Última visita: 02.05.2012.

Muñoz Rengel, Juan Jacinto (2010): "La narrativa fantástica en el siglo xxı". En: Roas, David y Casas, Ana (eds.): íNSULA: Lo fantástico en España (1980-2010), n. 765, pp. 6-10.

Olgoso, Ángel (2007): "Los palafitos". En: Los demonios del lugar. Córdoba, Almuzara, pp. 45-64.

Platón (2011): Timeo. Madrid, Gredos.

Ryan, Marie-Laure (2012): "Space". En: Hühn, Peter et al. (eds.): The Living Handbook of Narratology. Hamburgo, Hamburg University Press. hup.sub.uni-hamburg.de/lhn/ index.php?title=Space\&oldid=1708. Última visita: 02.05.2012.

Roas, David (ed.) (2001): Teorías de lo fantástico. Madrid, Arco/Libros.

Roas, David (2011a): "Cronologías alteradas: la perversión fantástica del tiempo". [En prensa]

- (2011b): Tras los límites de lo real: Una definición de lo fantástico. Madrid, Páginas de espuma.

Todorov, Tzvetan (1970): Introduction à la littérature fantastique. París, Seuil.

Vax, Louis (1973): Arte y literatura fantásticas. Buenos Aires, Eudeba.

Westphal, Bertrand (2007): La Géocritique: Réel, fiction, espace. París, Minuit. 